\title{
Challenges in Early Postnatal Care and Growth in Extremely Low Birth Weight Infants: A Multi-Center Study
}

\section{Shuaijun Li}

Peking University First Hospital

Qi Feng ( $\square$ fengqizf@126.com)

Peking University First Hospital https://orcid.org/0000-0001-7321-6134

\section{Xiao-mei Tong}

Peking University Third Hospital

\section{Qiu-ping Li}

Bayi Children's Hospital

\section{Jun-Yi Wang}

The First Hosipital of Tsinghua University

\section{Ya-Juan Wang}

Beijing Obstetrics and Gynecology Hospital,Capital Medical University

\section{Wei-Peng Liu}

Sixth Medical Center of PLA General Hospital

\section{Chao-Mei Zeng}

Peking University People's Hospital

\section{Dan-Hua Wang}

Peking Union Medical College Hospital

\section{Wen-Li Zhao}

PLA Force Rocket Force Characteristic Medical Crenter

\section{Li-Hua Li}

Beijing LuHe Hospital,Capital Medical University

\section{Hong Cui}

Beijing Friendship Hospital,Capital Medical University

\section{Ming-Yan Hei}

Beijing Children's Hospital,Capital Medical University

\section{Li Li}

Children's Hospital,Medical Institute of Pediatrics

\section{Xue-Feng Zhang}

Fifth Medical Center of PLA General Hospital

Jiu-Ye Guo 
Chaoyang Maternal and Child Health Hospital of Beijing

\section{Ming Yang}

Beijing United Family Hopital

\section{Research article}

Keywords: extremely low birth weight, growth retardation, growth, infants, preterm, weight gain, Z score

Posted Date: July 23rd, 2020

DOI: https://doi.org/10.21203/rs.3.rs-44343/v1

License: (c) (i) This work is licensed under a Creative Commons Attribution 4.0 International License. Read Full License 


\section{Abstract \\ Background}

Postnatal care and growth in extremely low birth weight (ELBW) infants are being increasingly focused on worldwide. However, few data from China have been reported, expecially multicenters. This multicenter study was designed to investigate the problems existing in postnatal care, weight gain and the related risk factors in in-patient ELBW infants.

\section{Methods}

Eligible ELBW infants admitted to involved neonatal intensive care units (NICUs) in 2017 in Beijing were studied retrospectively. Except for general early outcomes, Weight $Z$ score and feeding practice related information was caculated, and collected. Growth retardation (GR) was diagnosed if body weight Z score at discharge dropped more than one standard deviation (SD) compared with birth.

\section{Results}

Of our cohort of 137 ELBW infants, 92 infants discharged with medical advice were analyzed. Full enteral feeding reached at $37.0(27.0,51.8)$ days. Exclusive breast milk feeding rate was $30.4 \%$ at discharge. All infants had decreased weight $Z$ score, and its change was similar in different weight subgroups. The incidence of GR was $66.3 \%$. Multiple-factor analysis showed the risk factors for GR were small for gestational age(OR $34.768,95 \% \mathrm{Cl} 1.652-731.728)$, average weight gain rate $<15 \mathrm{~g} /(\mathrm{kg} . \mathrm{d})(\mathrm{OR} 249.062$, 95\% Cl 11.211-5532.889), and non-invasive and/or mechanicl ventilation duration > 28days(OR 6.867, $95 \% \mathrm{Cl} 1.211-38.957), P \otimes 0.05$. Keeping ELBW infants staying in hospital longer was beneficial to their weight gain $(\mathrm{OR}=0.950,95 \% \mathrm{Cl} 0.909-0.993, P<0.05)$.

\section{Conclusion}

Maintaining appropriate weight gain in early age is still a great challenge in ELBW infants. Fetal growth, early nutrition and sickness are critical influencing factors.

\section{Background}

In recent decades, great improvement in perinatal and neonatal health care has been made in China. Neonatal mortality decreased dramatically, from $25 \%$ in 1990 to $8 \%$ in $2013^{(1)}$. Preterm birth (delivered before 37 weeks gestation) complications are major results in neonatal death, accounting for $35 \%$ neonatal death rate ${ }^{(2)}$ and are also leading causes of mortality under 5 globally ${ }^{(3)}$. Not only high demise rate, but preterm infants are also highly risky to cognition, movement and behavior problems ${ }^{(4)}$. Early 
nutrition strategy underlies the basis for treatment of preterm infants, and guarantees their physical

growth, disease recovery, and good long-term outcome ${ }^{(5)}$. The early growth of preterm infants is affected by a variety of factors, and early nutritional management played an important role in it. The preterm infants admitted to neonatal intensive care unit (NICU) are especially high risk infants for early growth failure that was defined as extrauterine growth retardation (EUGR) or growth retardation (GR) ${ }^{(6,7)}$. Extremely low birth weight (ELBW) infants are ones whose birth weight less than $1000 \mathrm{~g}$. Generally, they are low in birth weight, small in gestational age, and suffer from intrauterine growth troubles and maternal-fetal complications. ELBW infants are the highest risky infants for high mortality and disability rate. In Japan, the mortality of ELBW infants from 2003 to 2008 was $17.7 \%$ 25.6\%, while in Hungary, such a mortality rate from 2011 to 2015 was $30 \%(8,9)$. A follow up study on ELBW infants with gestational age (GA) 22-26wk in Finland showed that the incidence of cerebral palsy was $11 \% \sim 14 \%(10)$.

As shown by the data of multi-center studies conducted in 2011 and from 2008 to 2012 in China, the mortality rates of ELBW infants were $50.0 \%$ and $50.3 \%$, respectively $(11,12)$, indicating a significant difference from the developed countries. Previous studies found that the growth of ELBW infants in NICU would have an important influence on the growth and development at $18 \sim 22$ months' corrected age ${ }^{(13)}$. Dueing to the relatively developed economy, medicine and well established citizen medical insurance system, Beijing is one of the lowest neonatal mortality cities in China, $1.52 \%$ in $2015^{(14)}$. The majority of general hospitals, children's hospitals and maternal and child health hospitals in Beijing have their own NICUs, and most of NICUs are well equipped. But the fact is that most NICUs have limited bed number, so ELBW infants management is distributed. Under the circumstance, We conducted this multicenter study in Beijing area to summarize and analyze the challenges in ELBW infants treatment, and provided some improvement suggestions. This paper focuses on ELBW infants early in-patient care, weight gain, and its influencing factors.

\section{Methods}

\section{Subjects}

This was a retrospective multicenter study in Beijing area, with cooperation of regional neonatal specialist association. All units having ELBW infants (birth weight $<1000 \mathrm{~g}$ ) admission and therapy were invited to participate in this study. ELBW infants, including outborn infants transferred to included centers, admitted within $48 \mathrm{~h}$ after birth in 2017 were included. Exclusion criteria: The infants had any severe congenital malformations, hereditary or metabolic disorders, and no available medical records.

\section{Data collection and Grouping}

2.1 Data collection: Data collected was put into the designed Epidata database designed for this study and was collected, stored and analyed in Department of Pediatrics, Peking University First Hospital, which coordinated this study. Data collected from all eligible ELBW infants included: demographics, major 
complications, therapy: outcomes, weight gain calculated and weight $Z$ score change calculated during hospitalization.

2.2 Grouping: According to discharge conditions and birth weight, they were divided into discharge with medical advice group and without medical advice group, and birth weight $<750 \mathrm{~g}, 750-<900 \mathrm{~g}$ and 900 $<1000$ g group.

\section{Diagnostic criteria}

3.1 Definitions and diagnostic criteria: (1) SGA: birth weight was lower than the 10th percentile (P10) for a specific GA by gender, evaluated by Fenton growth chart ; (2) Weight Z score=(the measured value - the average value at the same gestational age)/the standard deviation at the same gestational age; (3) GR: defined as reduction in weight $Z$ score between birth and discharge $\geq 1$ standard deviation (SD); (4) cholestasis: Total bilirubin $\leq 5 \mathrm{mg} / \mathrm{dl}$, while direct bilirubin $\geq 1 \mathrm{mg} / \mathrm{dl}$; total bilirubin $>5 \mathrm{mg} / \mathrm{dl}$, while direct bilirubin $>20 \%$ total bilirubin; (5) Breast milk feeding at discharge: Breast milk volume $>0 \mathrm{ml}$ or total breast milk feeding within 72 hours before discharge; (6) Non-invasive ventilation (NIV) and mechanical ventilation (MV): the assisted ventilation without or with endotracheal intubation. (7) Complications, respiratory distress syndrome(RDS) ${ }^{(16)}$, BPD defined as oxygen usage at 36 weeks' corrected gestational age ${ }^{(17)}$, more than and equal $(\geq)$ Stage II necrotizing enterocolitis $(\mathrm{NEC})^{(18)}$, intraventricular heamorrhage(IVH) and classification ${ }^{(19)}$, and late-onset sepsis (LOS) ${ }^{(20)}$ were diagnosed and managed according to the relevant references.

3.2 Outcome criteria: (1) discharge with medical advice: Infant with stable vital signs, full enteral feeding, body weight $>1800 \mathrm{~g}$, discharge order was given by physician; (2) discharge without medical advice: including death due to invalid rescue; terminating therapy in critical conditions, or request earlier discharge without fully stabilized or enteral feeding; transfer to other centers for surgical treatment.

3.3 Growth evaluation: Body weight worked as growth index for its accuracy. Body weight obtained daily with infant's scale. Body weight percentile and Z score were evaluated by Fenton growth chart (2013)(14) or WHO growth standard in infants $\mathrm{GA} \leq 42 \mathrm{wk}$ or $\mathrm{GA}>42 \mathrm{wk}$ respectively. Weight gain rate was calculated with equation, $[\mathrm{g} /(\mathrm{kg} \cdot \mathrm{d})]=\left[1000 \times \ln\right.$ (discharge weight/birth weight)]/length of stay ${ }^{(21)}$.

\section{Nutrition scheme}

The guideline for clinical practice of nutrition support in Chinese neonates (2013) ${ }^{(22)}$ was followed. Full enteral feeding was determined based on adequate intestinal feeding, no need for parenteral nutrition support, and stopping amino acids intravenous administration.

\section{Ethics}

The study was evaluated and approved by "Biomedicine Ethics committee of Peking University First Hospital" . 


\section{Statistics}

The data of normal distribution were expressed by $\overline{\mathrm{x}} \pm s$, and the comparison among groups was performed through independent $t$-test. The data of skewed distribution were expressed by $M\left(Q_{1}, Q_{3}\right)$, and the comparison among groups was performed through rank-sum test. The categorical variables were compared with Person $\chi 2$ or Fisher's exact test; a multiple-factor analysis was performed with the binary logistic regression analysis (Enter method). The statistical analysis was performed with SPSS version 22.0 software (IBM Corporation, NY). $P<0.05$ was considered statistically significant.

\section{Results}

\section{General characteristics of subjects}

Sixteen NICUs participated in this study. All city-level and district-level neonatal care centers and transfer centers were involved. Of the 16 NICUs, there were 12 general hospitals, 2 children's hospitals, and 2 maternal and children's hospitals. In 2017, there were 139 ELBW infants admitted in centers. Excluding 2 infants without medical records, 137 ELBW infants were eligible for study.

The median admitting age of ELBW infants was $0.50(0.25,1.25) \mathrm{h}$ (h means hours), 46 (33.6\%) were transferred from other hospitals; the mean maternal age was (33.2 \pm 4.0$)$ years, $38(27.7 \%)$ accepted assisted reproduction, 72 (52.6\%) had gestational complications (chronic hypertension, gestational hypertension, diabetes/gestational diabetes), and 28 (20.4\%) subjected to natural premature rupture of membrane.

Of our cohort of 137 ELBW infants, $92(67.2 \%)$ and 45 (32.8\%) discharged with and without medical advice, respectively. Among the latter 45 ELBW infants, 33 (24.1\%) were discharged within 14d after birth(median hospital stay was 4 days, d means days); 34 (24.8\%) withdrew therapy, 5 (3.6\%) failed therapy, and $6(4.4 \%)$ transferred for operation dueing to retinopathy of preterm infants (ROP), patent ductus arteriosus (PDA), or NEC. (Fig. 1 and Table 1). 
Table 1

General characteristics of ELBW infants discharged with and without medical advice

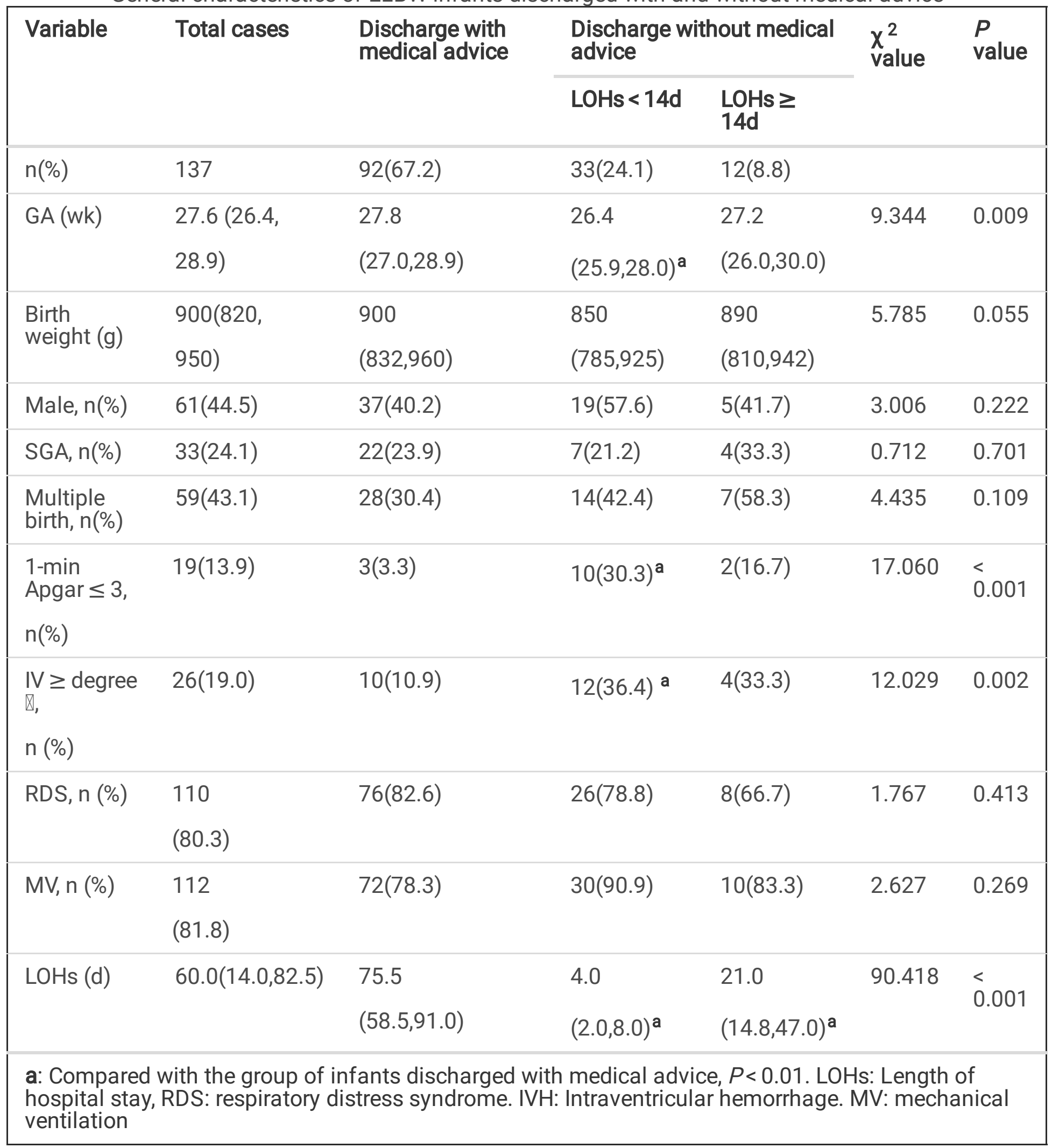

$80.3 \%$ of ELBW infants suffered from RDS and most of them had been mechanically ventilated. Compared with infants discharged with medical advice, the infants discharged without medical advice were more immature and had more severe early complications, ie. lower Apgar score and more severe 
IVH. $(P<0.01)$.No statistical difference in birth weight, multiple birth, and SGA proportion existed. See Table 1.

\section{Nutritional practice in ELBW infants discharged with medical advice}

\subsection{Basic characteristics of ELBW infants discharged with medical advice}

92(67.2\%) of this cohort of 137 ELBW infants discharged with medical advicel. Infants discharged with medical advice were grouped by birth weight: $<750 \mathrm{~g}, 750-<900 \mathrm{~g}$ and $900-<1000 \mathrm{~g}$. SGA infants accounted for $23.9 \%(22 / 92)$. The smaller the birth weight was, the lower the birth weight $Z$ score would be $(P<0.001)$. There was no statistical difference in $\mathrm{GA}$ (median $27.4 \mathrm{wk}, 27.5 \mathrm{wk}$ and $28.0 \mathrm{wk}$ for three groups above, respectively, $P=0.540$ ), SGA proportion( $25.0 \%, 34.4 \%$ and $17.3 \%$ for three groups above, respectively, $P=0.204$ ), respiratory support duration(median $45.0 \mathrm{~d}, 38.3 \mathrm{~d}$ and $35.8 \mathrm{~d}$ for three groups above, respectively, $P=0.137)$, chronic respiratory complications $(75.0 \%, 53.1 \%$ and $51.9 \%$ for three groups above, respectively, $P=0.489$ ). Although infants $<750 \mathrm{~g}$ seem stayed longer in hospital, but the difference had no statistic significance $(P=0.107)$. See Table 2 . 
Table 2

Basic characteristics of ELBW infants discharged with medical advice

\begin{tabular}{|c|c|c|c|c|c|c|}
\hline variable & $\begin{array}{l}\text { Total } \\
\text { cases }\end{array}$ & $<750 \mathrm{~g}$ & $\begin{array}{l}750- \\
<900 \mathrm{~g}\end{array}$ & $\begin{array}{l}900- \\
<1000 \mathrm{~g}\end{array}$ & $\begin{array}{l}\chi^{2} \\
\text { value }\end{array}$ & $\begin{array}{l}P \\
\text { value }\end{array}$ \\
\hline$n(\%)$ & 92 & $8(8.7)$ & $32(34.8)$ & $52(56.5)$ & & \\
\hline \multirow[t]{2}{*}{ GA (wk) } & 27.8 & 27.4 & 27.5 & 28.0 & \multirow[t]{2}{*}{1.233} & \multirow[t]{2}{*}{0.540} \\
\hline & $(27.0,28.9)$ & $\begin{array}{l}(26.4 \\
28.2)\end{array}$ & $\begin{array}{l}(26.8 \\
29.7)\end{array}$ & $\begin{array}{l}(27.0 \\
28.9)\end{array}$ & & \\
\hline \multirow[t]{2}{*}{ Birth weight (g) } & 900 & 710 & 840 & 955 & \multirow[t]{2}{*}{70.956} & \multirow{2}{*}{$\begin{array}{l}<.001 \\
0.001\end{array}$} \\
\hline & $(832,960)$ & $\begin{array}{l}(652 \\
720)^{a}\end{array}$ & $\begin{array}{l}(800 \\
870)^{a}\end{array}$ & $(912,978)$ & & \\
\hline SGA, n (\%) & $22(23.9)$ & $2(25.0)$ & $11(34.4)$ & $9(17.3)$ & 3.177 & 0.204 \\
\hline \multirow[t]{2}{*}{ Birth weight Z score } & -0.6 & -1.2 & -0.8 & -0.4 & \multirow[t]{2}{*}{13.655} & \multirow[t]{2}{*}{0.001} \\
\hline & $(-1.2,0.0)$ & $\begin{array}{l}(-1.6 \\
-1.1)^{b}\end{array}$ & $\begin{array}{l}(-1.5 \\
-0.4)^{\mathrm{c}}\end{array}$ & $(-0.9,-0.2)$ & & \\
\hline $\begin{array}{l}\text { oxygen therapy at CGA } \\
36 \mathrm{wk} \text {, }\end{array}$ & $50(54.3)$ & $6(75.0)$ & 17(53.1) & $27(51.9)$ & 1.438 & $0.489 *$ \\
\hline $\mathrm{n}(\%)$ & & & & & & \\
\hline \multirow{2}{*}{$\begin{array}{l}\text { NIV and/or MV duration } \\
\text { (d) }\end{array}$} & 37.6 & 45.0 & 38.3 & 35.8 & \multirow[t]{2}{*}{3.969} & \multirow[t]{2}{*}{0.137} \\
\hline & $\begin{array}{l}(22.2 \\
56.6)\end{array}$ & $\begin{array}{l}(37.0 \\
75.5)\end{array}$ & $\begin{array}{l}(26.0 \\
70.0)\end{array}$ & $(18.6,52.2)$ & & \\
\hline Postnatal steroids, n(\%) & $44(47.8)$ & $7(87.5)$ & 13(40.6) & $23(44.2)$ & 5.819 & $0.057 *$ \\
\hline \multirow[t]{2}{*}{ LOHs (d) } & 75.5 & 88.5 & 75.5 & 71.0 & \multirow[t]{2}{*}{4.446} & \multirow[t]{2}{*}{0.107} \\
\hline & $(58.5,91.0)$ & $\begin{array}{l}(70.8 \\
98.0)\end{array}$ & $\begin{array}{l}(62.2, \\
93.0)\end{array}$ & $\begin{array}{l}(56.0, \\
86.8)\end{array}$ & & \\
\hline
\end{tabular}

\subsection{Nutritional practice}

The feeding strategy based on intiation of enteral feeding was implemented actively after birth. The ratio of first feeding with breastmilk was $20.7 \%(19 / 92)$, and the ratio in infants $<750 \mathrm{~g}$ was zero(0/92). By the time of discharge, $57.6 \%(53 / 92)$ of the ELBW infants were breast milk feeding, and the ratio of exclusive breast milk feeding reached $30.4 \%(28 / 92)$. Full enteral feeding was achieved in all weight groups, at median $37.0 \mathrm{~d}(27.0,51.8)$. There was no statistical difference among groups in the incidence of NEC $\geq$ stage $I(P=0.064)$ and cholestasis $(P=0.485)$. See Table 3 . 
Table 3 Nutritional practice and complications in different birth weight groups,

cases $(\%)$

\begin{tabular}{|c|c|c|c|c|c|c|}
\hline Variable & Total cases & $<750 \mathrm{~g}$ & $750-<900 \mathrm{~g}$ & $900-<1000 \mathrm{~g}$ & $\mathrm{X}^{2}$ value & $P$ value \\
\hline $\mathrm{n}(\%)$ & 92 & $8(8.7)$ & $32(34.8)$ & $52(56.5)$ & & \\
\hline \multirow[t]{2}{*}{ Initiating enteral feeding (d) } & 2.0 & 1.5 & 2.0 & 2.0 & 0.143 & 0.931 \\
\hline & $(1.0,3.8)$ & $(1.0,8.8)$ & $(1.0,3.8)$ & $(1.0,3.8)$ & & \\
\hline First feeding with breast milk, $\mathrm{n}(\%)$ & 19(20.7) & 0 & $7(21.9)$ & $12(23.1)$ & 2.298 & 0.317 \\
\hline \multirow[t]{2}{*}{ Reaching full enteral feeding (d) } & 37.0 & 38.5 & 39.0 & 37.0 & 1.044 & 0.593 \\
\hline & $(27.0,51.8)$ & $(26.8,65.0)$ & $\begin{array}{l}(28.0, \\
52.0)\end{array}$ & $(25.5,51.0)$ & & \\
\hline $\begin{array}{l}\text { Breast milk feeding at discharge, } \\
\mathrm{n}(\%)\end{array}$ & $53(57.6)$ & $4(50.0)$ & $20(62.5)$ & 29(55.8) & 0.575 & 0.750 \\
\hline $\begin{array}{l}\text { Exclusive breast milk feeding } \\
\text { at discharge, } \mathrm{n}(\%)\end{array}$ & $28(30.4)$ & $2(25.0)$ & 10(31.3) & 16(30.8) & 0.124 & 0.940 \\
\hline NEC $\geq$ stage $\square, n(\%)$ & $4(4.3)$ & $2(25.0)$ & $1(3.1)$ & $1(1.9)$ & 5.897 & $0.064^{*}$ \\
\hline Cholestasis,n(\%) & $14(15.2)$ & $2(25.0)$ & $6(18.8)$ & $6(11.5)$ & 1.448 & 0.485 \\
\hline
\end{tabular}

*: Fisher's exact test.

\section{Nutritional outcomes of ELBW infants at discharge}

By the time of medical discharge, all ELBW infants reached full-term GA, and their weight Z scores were lower than those at birth, the median decline was more than one, $-1.20(-1.88,-0.80) .66 .3 \%(61 / 92)$ of ELBW infants were diagnosed as GR at discharge. Mean velocity of weight gain was $14.7 \pm 2.4 \mathrm{~g} /(\mathrm{kg} . \mathrm{d})$, $13.4 \pm 2.0 \mathrm{~g} /(\mathrm{kg} . \mathrm{d}), 12.7 \pm 2.2 \mathrm{~g} /(\mathrm{kg} . \mathrm{d})$, respectively $(P<0.037)$. There were no statistical differences in weight, weight $Z$ score, weight $\Delta Z$ during hospitalization, rate of $\mathrm{GR}$ and $\mathrm{LOHs}(P>0.05)$ See Table 4. 
Table 4

Nutrition outcomes of ELBW infants in different birth weights at discharge

\begin{tabular}{|c|c|c|c|c|c|c|}
\hline variable & Total cases & $<750 \mathrm{~g}$ & $750<900 \mathrm{~g}$ & $\begin{array}{l}900- \\
<1000 \mathrm{~g}\end{array}$ & $\begin{array}{l}\chi^{2} \\
\text { value }\end{array}$ & $\begin{array}{l}P \\
\text { value }\end{array}$ \\
\hline n(\%) & 92 & $8(8.7)$ & $32(34.8)$ & $52(56.5)$ & & \\
\hline $\begin{array}{l}\text { Discharge weight(g), } \\
\text { median(IQR) }\end{array}$ & $\begin{array}{l}2325 \\
(2060,2660)\end{array}$ & $\begin{array}{l}2485 \\
(2302,2742)\end{array}$ & $\begin{array}{l}2295 \\
(1980,2800)\end{array}$ & $\begin{array}{l}2282 \\
(2060,2645)\end{array}$ & 1.139 & 0.566 \\
\hline $\begin{array}{l}\text { Discharge GA (wk), } \\
\text { median(IQR) }\end{array}$ & $\begin{array}{l}38.7 \\
(37.3,41.1)\end{array}$ & $\begin{array}{l}40.0 \\
(38.1,41.8)\end{array}$ & $\begin{array}{l}39.0 \\
(37.6,41.5)\end{array}$ & $\begin{array}{l}38.0 \\
(37.0,40.6)\end{array}$ & 3.796 & 0.150 \\
\hline $\begin{array}{l}\text { Weight gain rate, } \\
\mathrm{g} /(\mathrm{kg} \cdot \mathrm{d}) \text {,mean } \\
(\mathrm{SD})\end{array}$ & $13.1 \pm 2.2$ & $14.7 \pm 2.4^{a}$ & $13.4 \pm 2.0$ & $12.7 \pm 2.2$ & 3.429 & 0.037 \\
\hline $\begin{array}{l}\text { Discharge weight Z } \\
\text { score, } \\
\text { mean(SD) }\end{array}$ & $-1.96 \pm 1.16$ & $-2.2 \pm 0.5$ & $-2.2 \pm 1.2$ & $-1.8 \pm 1.1$ & 0.607 & 0.547 \\
\hline $\begin{array}{l}\text { weight } Z \text { score } \\
\text { change }(\Delta Z) \text {,median } \\
(\mathrm{IQR})\end{array}$ & $\begin{array}{l}-1.20 \\
(-1.88 \\
-0.80)\end{array}$ & $\begin{array}{l}-1.05 \\
(-1.28 \\
-0.50)\end{array}$ & $\begin{array}{l}-1.10 \\
(-1.90 \\
-0.90)\end{array}$ & $\begin{array}{l}-1.30 \\
(-1.20 \\
-0.80)\end{array}$ & 2.505 & 0.286 \\
\hline GR, n (\%) & $61(66.3)$ & $5(62.5)$ & $20(62.5)$ & $36(69.2)$ & 0.458 & 0.795 \\
\hline $\begin{array}{l}\mathrm{LOHs}(\mathrm{d}) \\
\text { median } \\
(\mathrm{IQR})\end{array}$ & $\begin{array}{l}75.5 \\
(58.5,91.0)\end{array}$ & $\begin{array}{l}88.5 \\
(70.8,98.0)\end{array}$ & $\begin{array}{l}75.5 \\
(62.3,93.0)\end{array}$ & $\begin{array}{l}71.0 \\
(56.0,86.8)\end{array}$ & 4.466 & 0.107 \\
\hline
\end{tabular}

\section{Risk factors of growth retardation during in-patient period}

We conducted a multiple-factor analysis, and assumed independent variables below were the risk factors causing GR, male infant, birth weight (g), GA (wk) at birth, SGA at birth, LOS, NEC $\geq$ stage II, PDA, oxygen usage at CGA36wk, cholestasis, total fluid intake $<150 \mathrm{ml} / \mathrm{kg} / \mathrm{d}$ at $28 \mathrm{~d}$ postnatally, time to full enteral feeding (d), postnatal steroid, LOHs (d), NIV and/or MV duration > 28d, average weight gain rate < $15 \mathrm{~g} /(\mathrm{kg} . \mathrm{d})$. Results showed that SGA at birth, average weight gain rate $<15 \mathrm{~g} /(\mathrm{kg} . \mathrm{d})$, NIV and/or MV duration $>28 \mathrm{~d}$ were risk factors posing GR $(P<0.05)$, and the LOHs $(\mathrm{d})$ was a protective factor $(P<0.05)$ See Table 5. 
Table 5

Logistic analysis on risk factors of growth retardation

\begin{tabular}{|c|c|c|c|c|c|c|c|c|}
\hline \multirow[t]{2}{*}{ Variable } & \multirow[t]{2}{*}{$\beta$} & \multirow[t]{2}{*}{ S.E. } & \multirow[t]{2}{*}{ Wald } & \multirow[t]{2}{*}{ df } & \multirow{2}{*}{$\begin{array}{l}P \\
\text { value }\end{array}$} & \multirow{2}{*}{$\begin{array}{l}\text { OR } \\
\text { value }\end{array}$} & \multicolumn{2}{|l|}{$95 \% \mathrm{Cl}$} \\
\hline & & & & & & & $\begin{array}{l}\text { Lower } \\
\text { limit }\end{array}$ & $\begin{array}{l}\text { Upper } \\
\text { limit }\end{array}$ \\
\hline SGA & 3.549 & 1.554 & 5.212 & 1 & .022 & 34.768 & 1.652 & 731.728 \\
\hline $\begin{array}{l}\text { Weight gain rate } \\
<15 \mathrm{~g} / \mathrm{kg} \cdot \mathrm{d}\end{array}$ & 5.518 & 1.582 & 12.164 & 1 & .000 & 249.062 & 11.211 & 5532.889 \\
\hline $\begin{array}{l}\text { NIV and/or MV duratio- } \\
n>28 d\end{array}$ & 1.927 & .886 & 4.734 & 1 & .030 & 6.867 & 1.211 & 38.957 \\
\hline LOHs(d) & -.051 & .023 & 5.114 & 1 & .024 & .950 & .909 & .993 \\
\hline
\end{tabular}

\section{Discussion}

In our study, $67.2 \%(92 / 137)$ of ELBW infants finished their in-patient therapy and discharged by physicians, other $32.8 \%(45 / 137)$ transferred, discharged without medical advice or died. The lower birth weight infants had lower birth weight $Z$ score. Median LOHs was $75.0 \mathrm{~d}, 66.3 \%(61 / 92)$ of them was diagnosed with GR. SGA, average weight gain $<15 \mathrm{~g} / \mathrm{kg}$.d, respiratotry support (NIV and/or MC) were risk factors for GR. Staying longer in NICU was helpful to early growth.

Generally, ELBW infants are those with GA $<28 w k$, just like our infants. It was reported in 2019 that preterm infants with GA $<28 w k$ accounted for $4.1 \%$ of preterm population globally in $2014{ }^{(23)}$. Although the proportion of ELBW infants is not high, they have higher mortality, morbidity and disability rate ${ }^{(24)}$. As some infants transferred for operation, the actual survival rate of ELBW infants in Beijing was higher than $67.2 \%$. This was higher than that reported in other studies from China $(11,12)$, but lower than the developed countries $(24,25)$. There is a report that Parental economical condition influences the outcomes of ELBW infants in other areas of China ${ }^{(11)}$. This paper focuses on the ELBW infants in Beijing area. Developed medicine, economy, and insurance system in Beijing underlie the steady foundation for ELBW infants' therapy, and contribute to the lower mortality. Most of infants with birth weight more than $900 \mathrm{~g}$ and higher proportion of SGA infants in our study may have a positive effect on lower mortality. ELBW infants' rescue dispersed in many centers may not be beneficial to experience accumulation in each NICU, and may have adverse effects on therapy and outcomes.

First 7 days is a fragile period for newborn infant and the death rate in this period accounts for more than $2 / 3$ of neonatal death ${ }^{(26)}$. Generally, ELBW infants discharged within $14 \mathrm{~d}$ after birth will succumb. Our ELBW infants all received intensive care in NICU, so we prolonged our early intervention and observation window to 14 days. We don't have information about the prognosis of the ones who discharged without medical advice 2 weeks later. Long-term follow-up information is not available in this study. 
Weight gain is associated with the growth and neurological outcome of preterm infants ${ }^{(27,28)}$. SGA and GR affect the health of infants, increase the society and family burden and the mortality rate of infants ${ }^{(29)}$. Researches showed that, dueing to EUGR, ELBW infants had a higher risk of multiple complications, including hindered growth at corrected 18-22 months, cerebral palsy, mental developmental index (MDI) $<70$ and neurodysplasia ${ }^{(30-32)}$. In our study, a high proportion of ELBW infants subjected to intrauterine growth restriction, reaching $24.1 \%$, which exposed our infants to relatively high risks of GR. That some more immature infants discharged before 14 days lightened our later growth care challange, and may have influence on our results. As some infants discharge after CGA 42 weeks, our study used GR instead of EUGR, but EUGR was included in GR. Currently, EUGR is still a serious problem for $\leq 34 \mathrm{w}$ preterm infants, and the risk factors leading to EUGR include gestational age, birth weight, BPD, and SGA $(7,33)$. Previous studies reported that the EUGR incidence of preterm infants with gestational age $\leq 32 \mathrm{w}$ was $57 \%-71 \%{ }^{(33-36)}$, and Chinese studies reported that the incidence of EUGR in preterm infants with birth weight $\leq 1200 \mathrm{~g}$ was $83.8 \%(37)$. In this literature, the overall survival rate of ELBW infants was higher than the domestic level, but approximately $2 / 3$ of ELBW infants suffered from $\mathrm{GR}$, defined as the decline of $\mathrm{Z}$ score more than one. Instead of weight percentile less than tenth in growth charts $^{(37)}$, the definition we used can exclude the influence of intrauterine growth retardation or SGA at birth, and the duration of hospitalization. International growth chart/standard used to evaluation renders our results comparable to other studies. Head circumference and length are very important indexes for physical growth, but their accuracy can't be guaranteed. We selected systemic and accurate body weight as our growth index ${ }^{(37)}$.

Chinese and international nutritional guidelines for newborns are used widely in China, including enteral and parenteral nutrition. Our ELBW infants initiated enteral feeding at relatively early age, but the progress delayed compared to the guideline of Canada ${ }^{(38)}$. Although some studies identified the safety and efficacy of early aggressive infant's feeding $(39,40)$, restrictive feeding practice, ie. prolonged parenteral nutrition and late achieved full enteral feeding, still exists in Chinese NICUs ${ }^{(41)}$. Our study demonstrated the same problem. Delayed reaching full enteral feeding contributes to the individual feeding policy in $\mathrm{NICU}$, individual physician' opinion and experience, infants' health conditions, and feeding milk property. Breast milk feeding and fortified breast milk feeding are increasingly emphasized and used in NICU in China ${ }^{(42,43)}$. In Beijing, the any and exclusive breastfeeding rate at discharge for ELBW infants reached $57.6 \%$ and $30.4 \%$, similar to that reported by Battersby $\mathrm{C}$ et al ${ }^{(44)}$ after breastfeeding improvement action in 2016 in England. Limited by lack of human milk bank, maternal health conditions and promotion efforts, only $20.7 \%$ of ELBW infants started feeding with breast milk. Our ELBW infants had lower NEC incidence than that previously reported in China ${ }^{(11)}$, this assigned to better ELBW infants management. But the lower NEC incidence was also influenced by early withdrawing therapy in very high risk infants and several severe NEC infants transferred to other hospitals.

This multicenter study with cooperation with local neonatologic association, almost all NICUs in local area are involved. Study conducted in an economy and medicine-developed area in China, and detailed 
information regarding early therapy and growth pattern of ELBW infants was investigated systematically. The therapy of ELBW infants can partly represent the development of neonatology in China. Study results illuminate the problems and the related risk factors, and that would be conducive to improve clinical management. The insufficiency of the study is that the number of ELBW infants is small in 1 year, only body weight as the physical growth index, and no follow-up information.

In conclusion, ELBW infants are highly risky of mortality and morbidity, whose treatment and comprehensive management are subjected to various challenges. Although relatively good therapeutic experence and ability in developed area in China, there is still a long way to go for better short and longterm outcome of ELBW infants.

\section{Declarations}

\section{Acknowledgements}

We would like to thank the participants and their parents, and the following clinicians who assisted in data recruitment: Hui Zhang, Ying Zhou, Department of Pediatrics, Peking University Third Hospital. WenYu Xie, Neonatal intensive care unit, BaYi children's hospital, the Seventh Medical Center of PLA General Hospital. Sha-Sha Fan, Department of Pediatrics, The First Hospital of Tsinghua University. Chen Kou, Zun-Jie Liu, Department of neonatology, Beijing Obstetrics and Gynecology Hospital, Capital Medical University. Wei-Peng Liu, Department of neonatology, the Sixth Medical Center of PLA General Hospital. Ya-Mei Huangshan, Department of Pediatrics, Peking University People's Hospital. Jin-Yu Li,Department of Pediatrics, Peking Union Medical College Hospital. Hong-Hong Qin, Department of Gynecology and Pediatrics, PLA Rocket Force Characteristic Medical Center. Xiao-Xiang Li,Children's Center, Beijing Luhe Hospital, Capital Medical University. Ya-Jing Li, Department of Pediatrics, Beijing Friendship Hospital, Capital Medical University. Lu Chen, Neonatal Center, Beijing Children's Hospital, Capital Medical University. YingWang,Department of neonatology, Children's Hospital, Capital Institute of Pediatrics. JinYan Weng, Department of Pediatrics, the Fifth Medical Center of PLA General Hospital. Jiu-Ye Guo, Department of neonatology, Chaoyang Maternal and Child Health Hospital of Beijing. Jiao Zhang, Department of Pediatrics, Beijing United Family Hospital.

\section{Author Contributions}

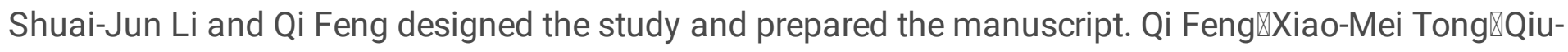

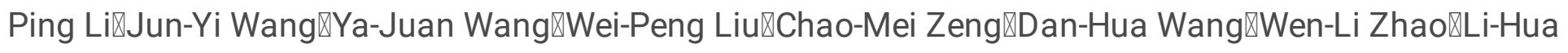

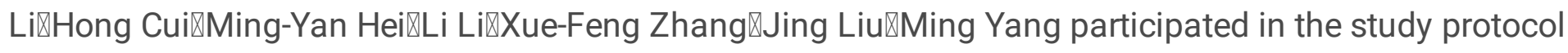
design and confirmation. They were responsible in guiding and instructing the protocol proceeding in each unit. Shuai-jun Li and Qi Feng had full access to all of the data in the study and took responsibility for the review, integrity of the data and statistical analysis. supervised the data collection and implemented the study. Shuai-jun Li and Qi Feng finalized the manuscript. Qi Feng: acts as the guarantor of the paper. 


\section{Funding}

This study had not received any sponsorship.

\section{Availability of data and materials}

The datasets generated and analyzed during the current study are available from the corresponding author on reasonable request.

\section{Ethics approval and consent to participate}

The study was evaluated and approved by "Biomedicine Ethics committee of Peking University First Hospital" . All methods were carried out in accordance with relevant guidelines and regulations. Written Informed consent was obtained from all the study subjects' parents before enrollment.

\section{Consent for publication}

Not appliable.

\section{Competing interests}

The authors declare that they have no conflict of interest.

\section{References}

1. UNICEF, Bank W , Division U P . Levels and trends in child mortality report 2017[J]. 2017.

2. Organization W H . Every newborn: an action plan to end preventable deaths[J]. Geneva Switzerland Who, 2014, 107(4):814-820.

3. Liu L , Oza S , Hogan D , Chu Y®Perin J, Zhu J囚et al. Global, regional, and national causes of under-5 mortality in 2000-15: an updated systematic analysis with implications for the Sustainable Development Goals[J]. The Lancet, 2016;388(10063):3027-35.

4. Guellec I, Lapillonne A, Marret S, Picaud J, Mitanchez D, Charkaluk M, et al. Effect of Intra- and Extrauterine Growth on Long-Term Neurologic Outcomes of Very Preterm Infants. The Journal of Pediatrics. 2016;175:93-9.

5. Sakurai M, Itabashi K, Sato Y, Hibino S, Mizuno K. Extrauterine growth restriction in preterm infants of gestational age $\leq 32$ weeks. PEDIATR INT. 2008;50:70-5.

6. Hu F, Tang Q, Wang Y, Wu J, Ruan H, Lu L, et al. Analysis of Nutrition Support in Very Low-Birth-Weight Infants With Extrauterine Growth Restriction. NUTR CLIN PRACT. 2018. 
7. Pampanini V, Boiani A, De Marchis C, Giacomozzi C, Navas R, Agostino R, et al. Preterm infants with severe extrauterine growth retardation (EUGR) are at high risk of growth impairment during childhood. EUR J PEDIATR. 2015;174:33-41.

8. Varga Péter, Berecz B , Gasparics ákos, Dombi Zsófia, Varga Z, Jeager J, et al. Morbidity and mortality trends in very-very low birth weight preterm infants in light of recent changes in obstetric care[J]. European Journal of Obstetrics \& Gynecology and Reproductive Biology, 2017, 211:134-139.

9. Kusuda S, Fujimura M, Uchiyama A, Totsu S, Matsunami K. Trends in morbidity and mortality among very-low-birth-weight infants from 2003 to 2008 in Japan. PEDIATR RES. 2012;72:531-8.

10. Tommiska V, Heinonen K, Lehtonen L, Renlund M, Saarela T, Tammela O, et al. No improvement in outcome of nationwide extremely low birth weight infant populations between 1996-1997 and 19992000. PEDIATRICS. 2007;119:29-36.

11. Lin HJ , Du LZ, Ma XL, Shi LP, Pan JH,Tong XM, et al. Mortality and Morbidity of Extremely Low Birth Weight Infants in the Mainland of China: A Multi -center Study.Chin Med J.2015,128:2743-50.

12. Collaborative Study Group for Extremely Preterm『Extremely Low Birth Weight Infant. Survival and mortality rate of extremely preterm and extremely low birth weight infants admitted to neonatology departments.Chin J Pediatr,2014.52:729-35.

13. Ehrenkranz, RA .Growth in the Neonatal Intensive Care Unit Influences Neurodevelopmental and Growth Outcomes of Extremely Low Birth Weight Infants[J]. PEDIATRICS, 2006.117:1253-61.

14. Dongyang Li, Jin Wang, Xuena Zhu. Mortality analysis of children under 5 years old in Beijing in 2015.Maternal \& Child Health Care of China. 2016;31.

15. Fenton TR, Kim JH. A systematic review and meta-analysis to revise the Fenton growth chart for preterm infants. BMC PEDIATR. 2013;13:59.

16. Sweet DG, Carnielli V, Greisen G, Hallman M, Ozek E, Plavka R, et al. European Consensus Guidelines on the Management of Respiratory Distress Syndrome - 2016 Update. NEONATOLOGY. 2017;111:107-25.

17. Jobe AH,Bancalari E.Bronchopulmonary Dysplasia. Am J Respir Crit Care Med,2001.163,1723-29.

18. Neu J. NECROTIZING ENTEROCOLITIS: The Search for a Unifying Pathogenic Theory Leading to Prevention. PEDIATR CLIN N AM. 1996;43:409-32.

19. Papile LA, Burstein J, Burstein $\mathrm{R}$, Koffler $\mathrm{H}$. Incidence and evolution of subependymal and intraventricular hemorrhage: a study of infants with birth weights less than 1,500 gm. J Pediatr. 1978 ;92:529-34.

20. Shane AL, Sánchez PJ, Stoll BJ. Neonatal sepsis. The Lancet. 2017;390:1770-80. 
21. Patel AL, Engstrom JL, Meier PP, Kimura RE. Accuracy of methods for calculating postnatal growth velocity for extremely low birth weight infants. PEDIATRICS. 2005;116:1466-73.

22. Pediatric Cooperative Group of Parenteral and Enteral Nutrition, Chinese Medical Association, et al. The guideline for clinical practice of nutrition support in Chinese neonates. Clin J Pediatr2013.34:782787.

23. Chawanpaiboon S, Vogel JP, Moller A, Lumbiganon P, Petzold M, Hogan D, et al. Global, regional, and national estimates of levels of preterm birth in 2014: a systematic review and modelling analysis. The Lancet Global Health. 2019;7:e37-46.

24. Stoll BJ, Hansen NI, Bell EF, Walsh MC, Carlo WA, Shankaran S, et al. Trends in Care Practices, Morbidity, and Mortality of Extremely Preterm Neonates, 1993-2012. JAMA. 2015;314:1039.

25. Jeschke E, Biermann A, Günster C, Böhler T, Heller G, Hummler HD, et al. Mortality and Major Morbidity of Very-Low-Birth-Weight Infants in Germany 2008-2012: A Report Based on Administrative Data. FRONT PEDIATR. 2016;4.

26. Haidong Wang, Chelsea A Liddell, Matthew M Coates, Meghan D Mooney, Carly E Levitz, Austin E Schumacher,et al. Global, regional, and national levels of neonatal, infant, and under-5 mortality during 1990-2013: a systematic analysis for the Global Burden of Disease Study 2013. Lancet. 2014; 384(9947): 957-79.

27. Pampanini V, Boiani A, De Marchis C, Giacomozzi C, Navas R, Agostino R, et al.Preterm infants with severe extrauterine growth retardation (EUGR) are at high risk of growth impairment during childhood. Eur J Pediatr . 2015;174:33-41.

28. Guellec I, Lapillonne A, Marret S,Picaud J,Mitanchez D, Charkaluk M, et al. Effect of Intra- and Extrauterine Growth on Long-Term Neurologic Outcomes of Very Preterm Infants. The Journal of Pediatrics. 2016;175:93-9.

29. Ray JG, Park AL, Fell DB. Mortality in Infants Affected by Preterm Birth and Severe Small-forGestational Age Birth Weight. PEDIATRICS. 2017;140.

30. Chien H, Chen C, Wang T, Hsu Y, Lin M. Neurodevelopmental outcomes of infants with very low birth weights are associated with the severity of their extra-uterine growth retardation. Pediatrics \& Neonatology. 2018;59:168-75.

31. Liao W, Lin M, Wang T, Chen C. Risk factors for postdischarge growth retardation among very-lowbirth-weight infants: A nationwide registry study in Taiwan. Pediatrics \& Neonatology. 2019.

32. Finken MJ, Dekker FW, de Zegher F, Wit JM. Long-term height gain of prematurely born children with neonatal growth restraint: parallellism with the growth pattern of short children born small for gestational age. PEDIATRICS. 2006;118:640-3.

Page 17/19 
33. Sakurai M, Itabashi K, Sato Y, Hibino S, Mizuno K. Extrauterine growth restriction in preterm infants of gestational age $\leq 32$ weeks. PEDIATR INT. 2008;50:70-5.

34. Clark RH, Thomas P, Peabody J. Extrauterine Growth Restriction Remains a Serious Problem in Prematurely Born Neonates. PEDIATRICS. 2003;111:986-90.

35. Embleton NE,Pang N and Cooke RJ. Postnatal Malnutrition and Growth Retardation: An Inevitable Consequence of Current Recommendations in Preterm Infants? Pediatrics 2001:270-73.

36. Tozzi MG, Moscuzza F, Michelucci A, Lorenzoni F, Cosini C, Ciantelli M, et al. ExtraUterine Growth Restriction (EUGR) in Preterm Infants: Growth Patterns, Nutrition, and Epigenetic Markers. A Pilot Study. FRONT PEDIATR. 2018;6.

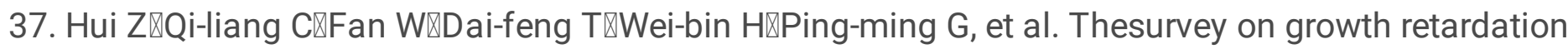
incidence of extremely and very low birth weight Chin Pediatr Emerg Med. 2013;20.

38. Dutta S, Singh B, Chessell L, Wilson J, Janes M, McDonald K, et al. Guidelines for Feeding Very Low Birth Weight Infants. NUTRIENTS. 2015;7(1):423-42.

39. Riskin A, Cohen K, Kugelman A, Toropine A, Said Aand Bader D. The Impact of Routine Evaluation of Gastric Residual Volumes on the Time to Achieve Full Enteral Feeding in Preterm Infants.J Pediatr .2017;189:128-34.

40. Morgan J , Bombell S, Mcguire W. Early trophic feeding versus enteral fasting for very preterm or very low birth weight infants[J]. Cochrane database of systematic reviews (Online), 2013;

41. Meiying Q, Changyan W, Yu Z, Zhonghong L, Danhua W. The early nutritional support strategies and postnatal growth in extremely low birth weight infants--trends of the last decade.Chin $\mathrm{J}$ Neonatol.2017;3.

42. Feldman-Winter L, Szucs K, Milano A, Gottschlich E, Sisk B, Schanler RJ. National Trends in Pediatricians' Practices and Attitudes About Breastfeeding: 1995 to 2014. PEDIATRICS. 2017;140.

43. Perrin MT. Donor Human Milk and Fortifier Use in United States Level 2, 3, and 4 Neonatal Care Hospitals. J PEDIATR GASTR NUTR. 2018;66:664-9.

44. Battersby C, Santhakumaran S, Upton M, Radbone L, Birch J, Modi N. The impact of a regional care bundle on maternal breast milk use in preterm infants: outcomes of the East of England quality improvement programme. Archives of Disease in Childhood - Fetal and Neonatal Edition. 2014;99:F395401.

\section{Figures}




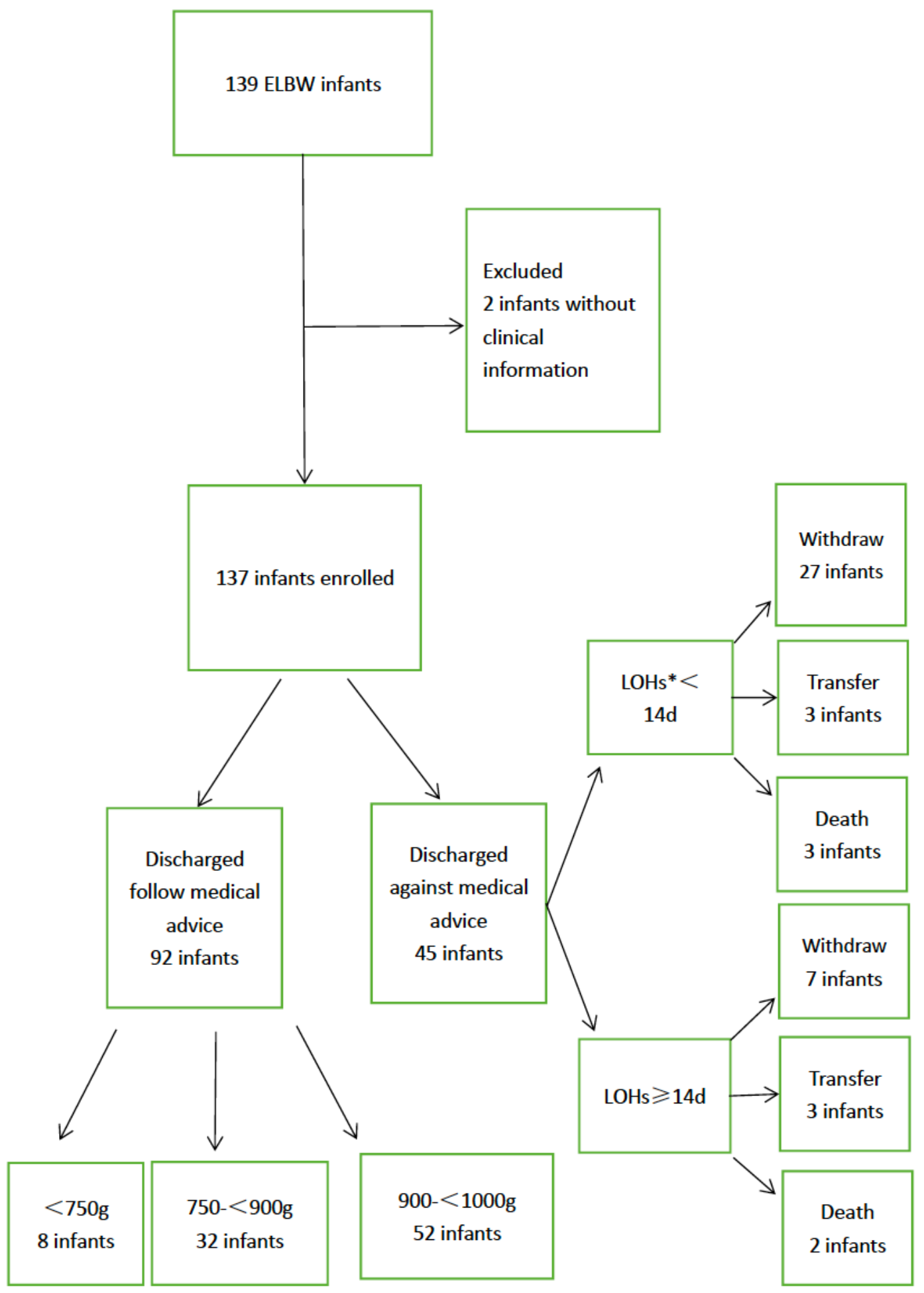

\section{Figure 1}

Study flowchart. *LOHs: Length of hospital stay 